\title{
New insights on trace metals behavior in the industrial impacted submarine Cassidaigne Canyon
}

\author{
S.H.M JACQUeT ${ }^{1 *}$, C. Chevalier ${ }^{1}$, O. HelorY ${ }^{2}$, D.
} MILlE $^{2}$, C. MONNIN ${ }^{3}$

${ }^{1}$ Aix Marseille Université, CNRS/INSU, Université de Toulon, IRD, Mediterranean Institute of Oceanography (MIO), UM 100, Marseille, France. (*correspondence: stephanie.jacquet@mio.osupytheas.fr; cristele.chevalier@mio.osupytheas.fr)

${ }^{2}$ CREOCEAN, Valparc - Bât B, 230 avenue de Rome, 83500 La Seyne sur Mer, France (herlory@creocean.fr mille@creocean.fr)

${ }^{3}$ CNRS-Université Paul Sabatier, IRD-OMP, Geosciences Environnement Toulouse GET, France (christophe.monnin@get.omp.eu)

Submarine concretions and a plume of white particles form when the high $\mathrm{pH}$ clarified Bayer effluent of the Gardanne alumina plant mixes with seawater in the Cassidaigne Canyon (NW-Mediterranean Sea). We determined the mineralogical and chemical (major and trace elements) compositions of these concretions and particles. They are mainly composed of hydrotalcite, a Mg-Al Double Layered Hydroxide. We also determined their formation rate, size distribution and settling rate. The capacity of hydrotalcite to store and release trace metals has been investigated during lab experiments and compared to the metal contents of water samples collected at sea in the water column. The stability of the hydrotalcite has also been studied through dissolution/precipitation experiments. Finally, dispersion and deposition of the particles have been simulated in the area of the effluent release. This work is part of an on-going investigation of the dynamics of trace metal contaminants and their impact on marine ecosystems in urbanized/industrial mediterranean coastal zones. 